\title{
Influence of coherent light on seed quality of Camelina sativa L.
}

\author{
Rima Kirakosyan, Inna Kapristova and Elena Kalashnikova* \\ Department of Biotechnology, faculty of agronomy and biotechnology, Russian State Agrarian University - Moscow Timiryazev \\ Agricultural Academy, Moscow, 127550 Russia
}

\begin{abstract}
Camelina sativa $\mathrm{L}$. is an underutilized Brassicaceae oilseed plant with a considerable agronomic potential for biofuel and vegetable oil production in temperate zones. Unlike most Brassicaceae, Camelina sativa L. is resistant to Alternaria black and many other diseases and pests. Camellia is a hardy plant; this allows it to grow in different soil and climate conditions. In addition, the crop does not require much use of pesticides. It is characterized by frost-resistance and relatively high growth rates at low temperatures, precocity and the ability to tolerate soil or air drought. The research investigates effect of coherent light on the seed quality of Camelina sativa L. It reveals that treating the seeds with coherent light for 60 and 120 seconds leads to an increase in their sowing qualities, plant productivity and changes of the seed quality.
\end{abstract}

\section{Introduction}

Camelina sativa $\mathrm{L}$. belongs to the family Brassicaceae, genera - Sisymbrieae. It has both spring- and winter plant varieties. This hardy crop is adapted to low fertility soils. The results from long-term experiments have shown that the yield of Camelina sativa are comparable to the yield of oilseed rape [1].

High oil content in Camelina sativa seeds (varying between 30-40 \%) renewed interest in Camelina sativa oil. Camelina sativa seeds have a high content of polyunsaturated fatty acids (about 50-60 $\%)$ with an excellent balance of useful fatty acids including 30-40 \% of alpha-linolenic acid, omega-3 and omega- 6 fatty acids. The $\omega-3 / \omega-$ 6 ratio for Camellia oil varies from 1.3 to 2 , whereas this value is significantly lower in canola oil $(\sim 0.52)$, soy oil $(\sim 0.15)$, safflower oil $(\sim 0.013)$, sunflower oil $(\sim 0.014)$, and corn oil $(\sim 0.018)$. Only in linseed oil, the $\omega-3 / \omega-6$ ratio is $\sim 4.2$. Thus, unlike many commonly used oils for human and animal consumption, Camellina oil is much more balanced in $\omega-3$ and $\omega-6$ fatty acids, providing a dietary source for both of these essential fatty acids [2].

Furthermore, Camelina sativa seeds contain polyunsaturated fatty acid, which is about $50 \%$ of the total amount of fatty acids. Therefore, the oil has a low oxidative stability. Like many other oils containing polyunsaturated fatty acids, Camellia oil contains many different molecules with antioxidant properties. Camellia oil is rich in tocopherols, with a total tocopherol content of 700 to $800 \mathrm{mg} / \mathrm{kg}$ of seeds. Camellina also has a high content of common phenolic compounds and flavonoids (143 mg/kg of seeds). Since many of these antioxidant molecules are found in the oil, this increases the overall oxidative stability of the oil. [3].

As Camelina sativa is a minor crop species, not much has been done in terms of its breeding aside from testing different accessions for agronomic traits and oil profiles [4]. As it was established in 1996 at the 3rd European Symposium on Industrial Crops and Products, France, mutation breeding induced variation in the fatty acid content by three- to four-fold.

Currently, the cultivation of oilseeds is of great importance due to their use as potential sources of oil production, as well as for generating environmentally friendly renewable fuels, biodiesel.

Camelina sativa attracts the attention of manufacturers and breeders due to the high productivity of seeds (more than $2 \mathrm{t} / \mathrm{ha}$ ), which contain $40-46 \%$ of drying oil.

The oil can be used in food, paint, soap as well as in medicine and perfume industries [5]. It is a good source of polyunsaturated fatty acids, such as linolenic and linoleic acids. Moreover, the oil contains antioxidants and relatively low concentration of erucic acid.

Recently, the influence of hormonal and physical factors on seeds has become widespread in order to increase the productivity of agricultural crops. Growth regulators are more commonly used in the research to increase plant productivity. For example, arachidonic acid, drugs based on silicon, hormones - cytokinins and auxins.

In recent years, coherent light has become more popular due to its physical properties. Its performance

* Corresponding author: kalash0407@mail.ru 
has been widely tested on fruit crops such as raspberries, blackberries, currants, actinidia, pears, apple trees, etc., in vitro and in vivo $[6,7]$. Such technologies have high biological efficiency, environmental cleanliness and low energy consumption [8]. However, work with agricultural plants in this direction is not numerous. As for Camelina sativa L., such work has not been carried out for this culture at all.

\section{Materials and methods}

In the research were studies 4 varieties of Camelina sativa L.: Isilkulets, Omich, VNIIMK 520, Crystal. Seeds were treated with coherent light before sowing.

\subsection{Laboratory research}

Seeds were irradiated with coherent light using a device LPI-2. Processing time was 15, 30, 60, 120, 240 seconds. The power density was $1-2 \mathrm{~W} / \mathrm{m}^{2}$. These expositions were based on our previous research [9]. Control variant of seeds was not processed. The following indicators were taken into account: vigor (\%), seed germination $(\%)$, and biometric indicators of seedlings $(\mathrm{cm})$. The vigor and germination rate were determined in accordance with GOST R 53325-2005 «Seeds of agricultural plants. Varietal and seed quality. General specifications».

Screening of the effect of coherent light on seed quality was processed in the laboratory at the Department of Biotechnology of the Russian State Agrarian University named after Timiryazev. Seeds have been grown in Petri dishes, on filter paper, moistened with water. The seeds were transferred to the light room with $23^{\circ} \mathrm{C}$ temperature, 16-hour photoperiod, lighting with white fluorescent lamps (OSRAL 36/25). The experiment has been repeated three times, each Petri dish contained 50 seeds.

\subsection{Field research}

Field research was conducted at the Timofeyev field experimental station at the RSAU-MTAA (Moscow). The area of each plot was $5 \mathrm{~m}^{2}$, and 300 seeds were sown in each variant.

Before sowing, the seeds were irradiated with coherent light for $15,30,60,120$ and $240 \mathrm{sec}$. In the control variant, the seeds were not processed.

The experiment has been repeated three times. The soil was sod-podzolic. The plants ripened in mid-August. The plants were harvested at the end of August.

\subsection{Biochemical research}

The method of spectrophotometry was used to determine the biochemical parameters of seeds. Infrared analyzer spectraStar XT («Unity Scientific», USA) was used in the experiment. The seeds were tested for the following parameters: moisture, fatty acids, fiber, protein, ash content. These indicators were assesed in each variant.

\subsection{Mathematical statistics}

Mathematical processing of experimental data was performed on the basis of methods of mathematical statistics [10]. Variance and regression analysis was performed on a computer using MS Excel.

\section{Results}

The research has shown that treating seeds with coherent light has different effect on vigor and seed germination rate. The results of laboratory tests are shown in Table 1.

Some patterns have been established: 1) in processing seeds for 15,30 and 240 seconds there is a decrease in vigor and seed germination rates, 2) in the processing of seeds for 60 and 120 seconds, the accounted rates were 10-20\% higher than the control variant. These patterns were typical for all the studied varieties of Camelina sativa $\mathrm{L}$.

Table 1. Influence of coherent light on the sowing qualities of Camelina sativa $\mathrm{L}$. seeds

\begin{tabular}{|l|c|c|c|c|c|c|}
\hline \multirow{2}{*}{$\begin{array}{c}\text { Plant } \\
\text { variety }\end{array}$} & \multicolumn{7}{|c|}{ Processing time, sec } \\
\cline { 2 - 7 } & 0 & 15 & 30 & 60 & 120 & 240 \\
\hline Omich & 75 & 65 & 78 & 83 & 85 & 70 \\
\hline Isilkulets & 72 & 65 & 75 & 80 & 83 & 70 \\
\hline Crystall & 79 & 70 & 70 & 85 & 85 & 72 \\
\hline $\begin{array}{l}\text { vniimk } \\
520\end{array}$ & 78 & 72 & 72 & 84 & 83 & 73 \\
\hline \multicolumn{7}{|c|}{ Seed germination, \% } \\
\hline Omich & 91 & 78 & 95 & 96 & 95 & 85 \\
\hline Isilkulets & 78 & 70 & 77 & 92 & 95 & 78 \\
\hline Crystall & 93 & 86 & 88 & 98 & 98 & 89 \\
\hline $\begin{array}{c}\text { vniimk } \\
520\end{array}$ & 81 & 77 & 78 & 94 & 95 & 79 \\
\hline
\end{tabular}

In addition to vigor and seed germination rates, we have also determined biometric indicators of 7-day-old seedlings. The research results are shown in Table 2.

Table 2. Influence of coherent light on biometric indicators of Camelina sativa L. seedlings

\begin{tabular}{|l|c|c|c|c|c|c|}
\hline \multirow{2}{*}{$\begin{array}{c}\text { Plant } \\
\text { variety }\end{array}$} & \multicolumn{7}{|c|}{ Processing time, sec } \\
\cline { 2 - 7 } & 0 & 15 & 30 & 60 & 120 & 240 \\
\hline Omich & 3.2 & 2.5 & 3.0 & 4.2 & 4.0 & 2.3 \\
\hline Isilkulets & 2.4 & 2.0 & 2.3 & 4.0 & 3.62 & 2.4 \\
\hline Crystall & 4.4 & 4.2 & 4.1 & 5.5 & 5.4 & 4.0 \\
\hline $\begin{array}{l}\text { vniimk } \\
520\end{array}$ & 2.9 & 2.3 & 2.4 & 3.8 & 4.0 & 2.9 \\
\hline \multicolumn{7}{|c|}{ Root length, cm } \\
\hline Omich & 1.2 & 0.6 & 0.7 & 1.6 & 1.5 & 1.0 \\
\hline Isilkulets & 0.3 & 0.2 & 0.3 & 1.0 & 1.0 & 0.4 \\
\hline Crystall & 1.9 & 1.5 & 1.6 & 2.8 & 3.0 & 1.5 \\
\hline $\begin{array}{c}\text { vniimk } \\
520\end{array}$ & 0.7 & 0.5 & 0.5 & 1.1 & 1.0 & 0.7 \\
\hline
\end{tabular}

Our research has shown that treating seeds with coherent light in different processing periods has both an 
inhibitory and stimulating effect on the biometric indicators of Camelina sativa L. seedlings. Thus, the seed treatment for 60 and 120 seconds led to increasing the hypocotyl length and seedlings' roots in comparison with the control variant by $30-50$ and $50-60 \%$, respectively. As for the processing options of 15, 30 and 240 seconds, the biometric indicators were lower or at the same level as control. This effect was typical for all the studied varieties of Camelina sativa $\mathrm{L}$.

The effect of coherent light on Camelina sativa L. must be tested not only in the laboratory, but also in the field. The ability to perform field evaluation is a necessary and in some studies a significant advantage allowing researchers to assess its performance beyond strictly controlled laboratory conditions. In the field plants are exposed to higher light intensity, seasonal daily variations in temperature and light, competition for nutrients, and watering regimes depending on natural weather conditions which can effect on plant productivity.

Field research was conducted at the Timofeyev Field Experimental Station at the Russian State Agrarian University - Moscow Timiryazev Agricultural Academy. Regardless of the variants, it is established that a mass seed germination occurred on the 5th day after sowing (Figure 1).

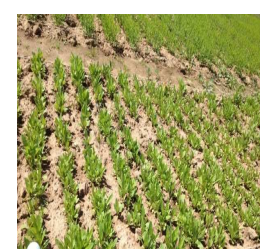

a

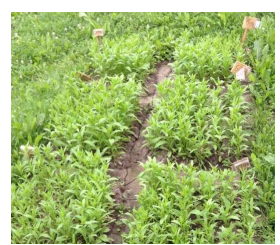

b

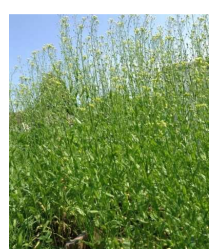

c
Figure 1. Camelina sativa L. at different stages of growth: a-sprouts, $\mathrm{b}$ - budding, $\mathrm{c}$ - flowering

It is observed that in the variants of seed treatment with coherent light for 60 and 120 seconds, plants rapidly passed through all phases of development. For example, in these variants, the phase of full ripeness occurred 5 days earlier than in the control variant and in other processing options, and the weight of 1000 seeds was $15 \%$ greater. As for such an indicator as the number of productive plant shoots, the average number of shoots was 3-4 pieces in the control and in the treatment options of 15,30 and 240 seconds, and in the options of 60 and 120 seconds it reached 5-8 pieces.

Plant productivity was higher not only because of the number of productive shoots, but also because of the size of the seeds (Figure 1 a,b). In all variants, the coherent light treatment has helped form full-fledged, developed, flat seeds. As for the control variant the seeds were small and underdeveloped (Figure $2 \mathrm{c}$ ).
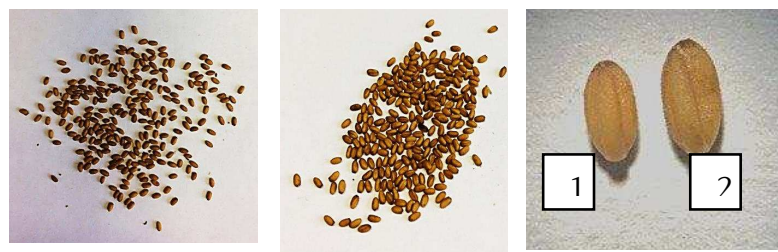

$\mathrm{b}$

Figure 2. Seeds of Camelina sativa L. in control (a) and treatment with coherent light for 60 seconds. The appearance of the seeds ( 1 - control, 2 - treatment $)$

Due to the fact that Camelina sativa $\mathrm{L}$. is a source of valuable oil, it is important to define not only productivity and yield, but also the quality of the oil of this plant. The seeds were tested for: moisture, fatty acids, fiber, protein, ash content. The method of spectrophotometry was used during the research.

Studies have shown that coherent light does not have a clear effect on the biochemical parameters of seeds. It can have both stimulating and inhibitory effects on the biosynthesis of the studied parameters. The results are available in Figures 3-7.

As a result of the research, it has been found that the processing time of seed treatment with coherent light does not have the same effect on the change in the qualitative composition of the oil of the studied varieties of Camelina sativa $\mathrm{L}$.

The use of coherent light had a significant effect on the content of moisture, fatty acids and ash content in the seeds.

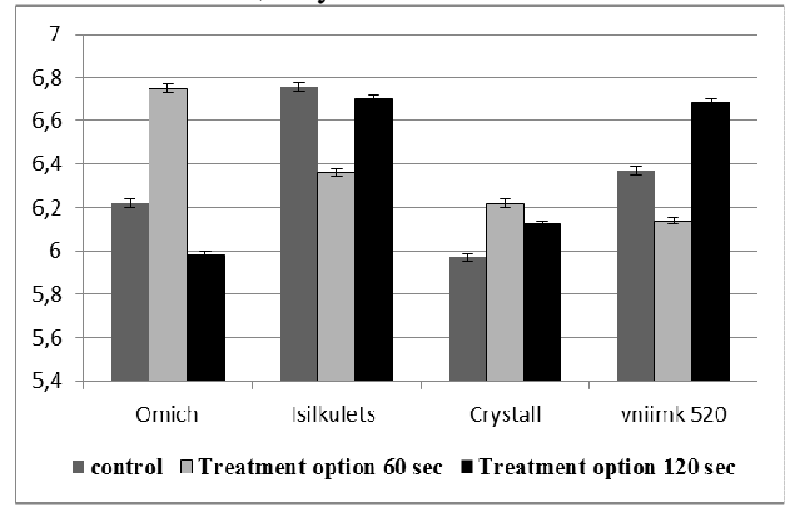

Figure 3. Influence of coherent light on moisture of Camelina sativa $\mathrm{L}$. seeds for different varieties

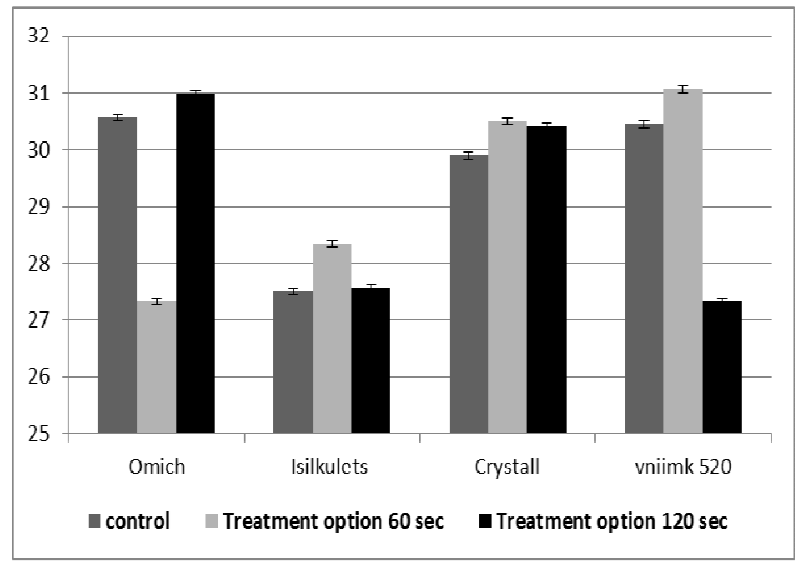

Figure 4. Influence of coherent light on fatty acids of Camelina sativa $\mathrm{L}$. seeds for different varieties 


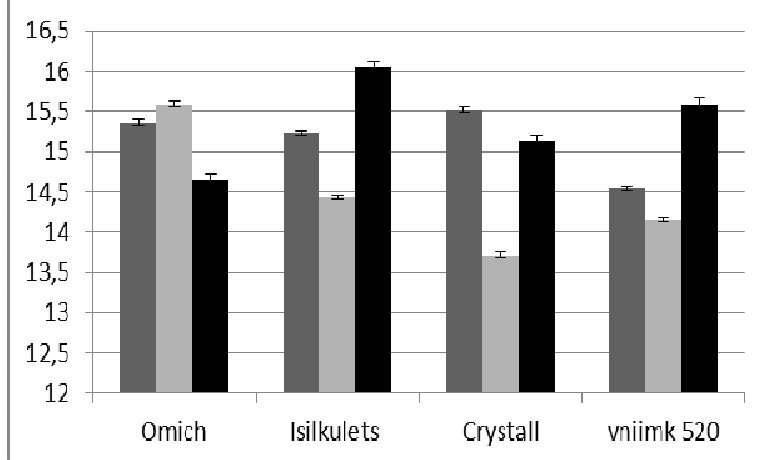

n control $\square$ Treatment option 60 sec $\square$ Treatment option 120 sec

Figure 5. Influence of coherent light on fiber of Camelina sativa $\mathrm{L}$. seeds for different varieties

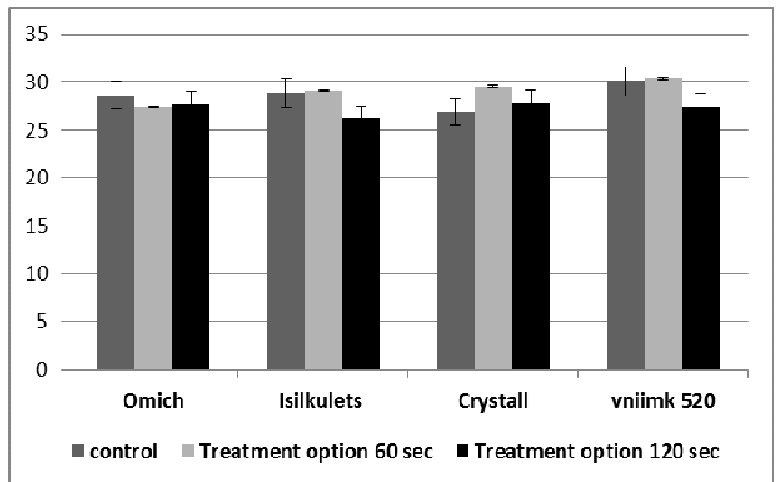

Figure 6. Influence of coherent light on protein of Camelina sativa $\mathrm{L}$. seeds for different varieties

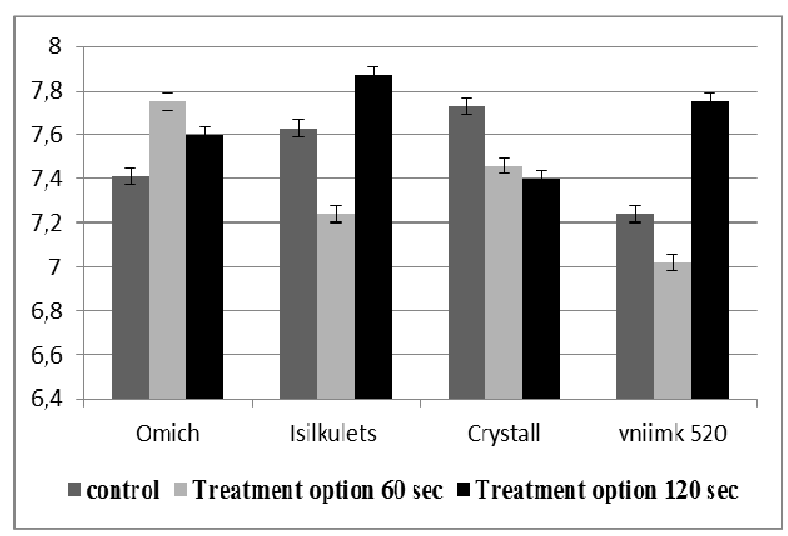

Figure 7. Influence of coherent light on ash content of Camelina sativa $\mathrm{L}$. seeds for different varieties

As for the effect of coherent light on the content of fiber in seeds, this indicator depended on the treatment variant and genotype.

It was found that coherent light had no effect on protein biosynthesis. In all processing variants, its values were at the level of the control variant. The exception was the Crystal variety. When treating seeds with coherent light for 60 seconds, an insignificant increase in protein content in the seeds was observed.

All results are summarized in Table 3 .

Table 3. Biochemical parameters of seeds of Camelina sativa $\mathrm{L}$

\begin{tabular}{|l|c|c|c|c|c|c|}
\hline Variety & $\begin{array}{c}\text { Treatment } \\
\text { option }\end{array}$ & $\begin{array}{c}\text { Mois- } \\
\text { ture }\end{array}$ & $\begin{array}{c}\text { Fatty } \\
\text { acids }\end{array}$ & $\begin{array}{c}\text { Ash } \\
\text { content }\end{array}$ & Fiber & Protein \\
\hline
\end{tabular}

\begin{tabular}{|l|c|c|c|c|c|c|}
\hline \multirow{2}{*}{ Omich } & 60 & $+*$ & - & + & + & - \\
\cline { 2 - 7 } & 120 & - & + & + & - & - \\
\hline \multirow{2}{*}{ silkulets } & 60 & - & + & - & - & - \\
\cline { 2 - 7 } & 120 & - & - & + & + & - \\
\hline \multirow{2}{*}{ Crystal } & 60 & + & + & - & - & + \\
\cline { 2 - 7 } & 120 & + & + & - & - & - \\
\hline \multirow{2}{*}{$\begin{array}{l}\text { vniimk } \\
5\end{array}$} & 60 & - & + & - & - & - \\
\cline { 2 - 7 } & 120 & + & - & + & + & - \\
\hline
\end{tabular}

Note: $*$ " + " indicator above the control option," - " indicator below the control option

Thus, when processing seeds of the Crystal variety with coherent light for 60 and 120 seconds, such indicators as humidity, the amount of fatty acids, protein in the seeds increase, and fiber and ash content are decreasing. For other varieties of Camelina sativa L., the considered indicators increase depending on the processing time of seed treatment with coherent light.

\section{Conclusion}

Camelina sativa L. is a plant in the family Brassicaceae with a unique seed oil. The composition of the oil includes such acids as linolenic, oleic, linoleic and eicosenic. There is interest in using this oil for industrial purposes, human nutrition and pharmaceuticals. Compared to B. napus L., Camelina sativa L. has a number of advantages, as it is more tolerant to insects, diseases and drought. Despite these useful properties of Camelina sativa L., to increase the commercial production of this crop, it is necessary to increase the yield of seeds, oil content and seed size $[11,12]$.

One of the most important breeding objectives is to increase seed size. Camelina small seed size $(\sim 1.5 \mathrm{~mm} \times 0.8 \mathrm{~mm}$, or $1 \mathrm{mg} / \mathrm{seed})$ [13] may hamper its incorporation into modern agriculture. An increase in the size of camellia seeds will lead to increased yields and to produce more oil. In addition, large seeds are necessary for the rapid emergence of seedlings and especially under less favorable growing conditions. From larger seeds, larger seedlings develop.

Morphophysiological processes can be controlled through chemical and physical factors. A promising direction is the use of coherent light.

It was shown that the short-term effect of coherent radiation on a biological object leads to increased gene expression. This allows plant cells to make fuller use of their genetic potential. In addition, it was found that lowintensity radiation has a pronounced photoregulatory effect, which manifests itself in a change in the metabolic and transcriptional activity of cells, an increase in the permeability of membranes, structural rearrangements of protein molecules, and the transmission of chemical signals directly to photosensitive genes.

Our studies have shown the effect of coherent light on the sowing quality of seeds in the laboratory. In addition, field studies have established a positive effect of pre-sowing seed treatment with coherent light on plant productivity and the quality of seed composition. 
Thus, application of environmentally friendly, resource-saving technologies using ionizing radiation sources is a promising area of research in agriculture. They enable rapid and more complete use of the genetic potential of cultivated plants, achieving high productivity. This is likely due to epigenetic changes in plant functional activity. However, these technologies require constant improvement.

\section{References}

1. T.Ya. Prakhova, Bull. of the Altai state Altai Univer. 9(107), 17-19 (2013)

2. J.L. Harwood, R.J. Weselake, Fatty Acids, Chem., Synthesis, and Applicat. 37-48 (2017)

3. B. Matthaus, J. Zubr, Industrial Crops and Products 12, 9-18 (2000)

4. K.A. McVay, P.F. Montana State University Extension, MontGuide, MT200701AG Revised 3/08 (2008)
5. D.T. Ehrensing, O. Guy Stephen, Oregon State University Extension Service, EM 8953-E, January. (2008)

6. A.V. Budagovsky, Theory and practice of laser treatment of plants (Publ. Michurinskaya of the Russ. Fed., 2008), 548 p.

7. A.V. Budagovsky, Laser diagnostics of plants: guidelines (Michurinsk, 2010), $69 \mathrm{p}$.

8. A.F. Balabak, Z.Ya. Ivanova, V.I. Lysikov, Izvestiya MSSR, Ser. Biolog. and Chem Sci. 3, 5-8 (1979)

9. I.I. Kapristova, E.A. Kalashnikova, New sci.: From idea to result 1-3, 20-22 (2017)

10. A.V. Smiryaev, A.V. Kilchevsky, Genetics of populations and quantitative traits (Koloss, Moscow, 2007), $250 \mathrm{p}$.

11. Y. Lixia, L. Runzhi, Frontiers in Plant Sci. 11 (2020)

12. D. Kurasiak-Popowska, B. Ryńska, K. StuperSzablewska, Agronomy 9(4), 168 (2019)

13. R.A. Fleenor, USDA Natural Resources Conservation Service (2011) 